\title{
CD44 and CD44v6 are Correlated with Gastric Cancer Progression and Poor Patient Prognosis: Evidence from 42 Studies
}

\author{
Min Fang Junrong Wu Xin Laib Huaying Aic Yifeng Tao ${ }^{a}$ Bo Zhu ${ }^{a}$ \\ Lingsha Huang ${ }^{a}$
}

aDepartment of Clinical Laboratory, The Affiliated Tumor Hospital of Guangxi Medical University, Nanning, bDepartment of Clinical Laboratory, The People's Hospital of Yingtan City, Yingtan, 'Department of Injection Room, The People's Hospital of Yingtan City, Yingtan, China

\section{Key Words}

$\mathrm{CD} 44 \cdot \mathrm{CD} 44 \mathrm{v} 6 \cdot$ Gastric cancer $\bullet$ Prognosis $•$ Meta-analysis

\begin{abstract}
Background/Aims: The prognostic power of the levels of total CD44 and its isoform CD44v6 for patients with gastric cancer (GC) remains controversial. Therefore, our study aims to generalize the clinicopathological and prognostic significance of these two proteins in GC. Methods: A literature search of the PubMed, Web of Science and Embase databases was conducted to identify eligible studies. The odds ratio (OR) with a $95 \%$ confidence interval (CI) was used to assess the effects. Results: In all, 42 studies including 6,229 patients were included in this analysis. Total CD44 was mentioned in 21 papers, and the results showed that CD44 was positively correlated with the $\mathrm{T}$ category, the $\mathrm{N}$ category, distant metastasis, lymphatic invasion and TNM stage. Moreover, patients with CD44 overexpression had a lower 5 -year overall survival $(\mathrm{OS})$ rate $(\mathrm{OR}=3.35,95 \% \mathrm{CI}=1.83-6.13)$. CD44v6 was mentioned in 24 studies, with results that were similar to those for total CD44. However, total CD44 or CD44v6 expression was not correlated with tumor size and histological grade. Conclusion: High CD44 or CD44v6 expression levels were correlated with cancer progression and poor prognosis in patients with GC. Both CD44 and CD44v6 may be useful diagnostic or prognostic biomarkers for GC.
\end{abstract}

\section{Introduction}

Although the incidence of gastric cancer (GC) has substantially declined in recent years, the disease still ranks fourth in incidence among all cancers and remains the second most deadly cancer worldwide [1]. The diagnosis and treatment of GC have improved significantly, though 5-year overall survival (OS) rate of patients with middle- and late- stage disease is M. Fang and JR Wu contributed equally to this work. 


\section{Cellular Physiology Cell Physiol Biochem 2016;40:567-578

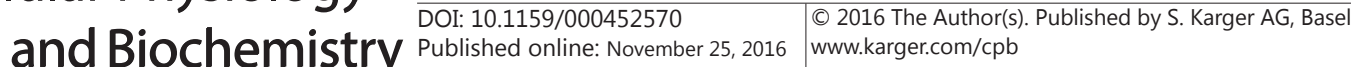 \\ Fang et al.: CD44 and CD44v6 are Correlated with Gastric Cancer Progression}

only $\sim 20 \%$ due to local recurrence as well as metastatic disease and drug resistance [2, $3]$. Recent research has suggested that cancer stem cells (CSCs), which represent a rare sub-population of cancer cells with the main properties of self-renewal and multipotency, may account for tumor initiation, metastasis, relapse, and resistance to chemotherapy or radiotherapy [4].

Several molecules have been reported to be useful markers in GC, such as CD44, CD133 and Hsa-miR-21, and high expression of these markers is usually indicative of a poor prognosis in patients with GC [5, 6]. Among these, the CD44 family is one of the most consistently reported markers in GC. The CD44 proteins, which are expressed in many cell types, belong to a polymorphic family of cell surface glycoproteins that were originally described as lymphocyte homing receptors [7]. However, the CD44 family plays critical roles in tumor occurrence, progression, and metastasis $[8,9]$, and members of this family have prognostic value in a wide variety of tumor types [10-13]. CD44 has recently been revealed as a target of the Wnt pathway, which is acknowledged as a key pathway for the maintenance of stemness in CSCs $[14,15]$. CD44v6 is the most frequently reported splicing variant member of the CD44 family in GC and studies have shown that increased expression of total CD44 or CD44v6 is related to GC invasion, lymph node metastasis and poor outcomes $[5,16,17]$.

The paradigm of CD44 or CD44v6 as a biomarker of CSCs has provoked numerous studies that exploring the prognostic significance of their expression in patients with GC. Despite these numerous independent studies, the prognostic value of CD44/CD44v6 in GC remains controversial. For example, Mayer et al. and Okayama et al. demonstrated high CD44 and CD44v6 expression in GC was to be correlated with poor clinical outcomes of GC patients $[18,19]$. Conversely, Kim et al. and Fanelli et al. found no obvious correlation between CD44/ CD44v6 and clinical outcomes of patients with GC [20,21], and Songun et al. reported a poor prognosis for CD44v6-negative patients [22]. To address these discrepancies, we performed a meta-analysis to examine the relationship of expression of total CD44 and its isoform CD44v6 with clinicopathological features of GC and to determine their value as diagnostic or prognostic markers for GC.

\section{Materials and Methods}

\section{Literature search and eligibility criteria}

We collected data until May 25, 2016, using a comprehensive literature search of the PubMed, Web of Science and Embase databases. The following search terms were used: "gastric carcinoma" or "gastric cancer" or "stomach neoplasms" and "CD44".

The studies included in the meta-analysis were randomized controlled studies or observational research (case control or cohort studies) evaluating the association between CD44/CD44v6 expression and GC clinicopathological features or prognosis. Eligible studies were included when the following criteria were met: (1) expression of the CD44 or CD44v6 protein was evaluated in cancer tissues by immunohistochemistry (IHC) rather than by serum analysis or any other type of detection method; (2) the relationship between the CD44/CD44v6 expression and clinicopathological characteristics of GC was evaluated, and the association of these markers with the 5-year OS rate was also evaluated; (3) the data for the 5-year OS rate were adequate and published; (4) the full-text articles were published in English or Chinese. Moreover, the references listed in the articles were also searched to avoid omission related studies.

\section{Data extraction}

All data from the eligible studies were extracted by two independent reviewers (Fang M and Wu JR) using predefined criteria. For every eligible study, the following data were assessed: the first author's name, publication year, country where the study was conducted, TNM stage of the patients, antibody used and cutoff scores for the definition of positive staining and the 5-year OS rate. We primarily examined the associations between total CD44/CD44v6 expression and certain clinicopathological parameters, including the $\mathrm{T}$ category, the $\mathrm{N}$ category, distant metastasis, histological grade, lymphatic invasion, vascular invasion, tumor size and TNM stage. More importantly, we investigated the association between CD44/CD44v6 


\section{Cellular Physiology Cell Physiol Biochem 2016;40:567-578

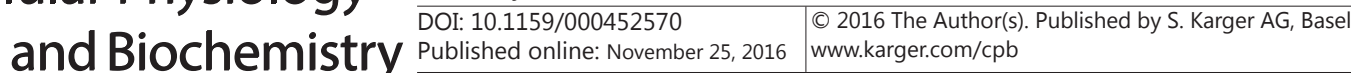 \\ Fang et al.: CD44 and CD44v6 are Correlated with Gastric Cancer Progression}

expression and the 5-year OS rate. For those articles that contained only a plotted Kaplan-Meier curve, the software GetData Graph Digitizer 2.24 was used to directly digitize the 5-year OS rate.

\section{Sensitivity analysis}

A sensitivity analysis was performed through via sequential omission of individual studies. With the exception of the 5-year OS rate for the CD44v6 analysis, it was found that no single study could alter the results demonstrating that the results of our meta-analysis were quite stable.

\section{Publication bias}

We utilized Begg's and Egger's tests to identify potential publication bias,. In general, the funnel plots did not show obvious evidence of asymmetry and the P-value of Egger's test was greater than 0.05. This indicated no publication bias in most of the pooled studies, except those studies for which the $\mathrm{N}$ category was included in the CD44v6 analysis. The detailed results of the P-value derived from Egger's test are summarized in Tables 3-4.

\section{Statistical analysis}

The strength of the association between total CD44/CD44v6 expression and clinicopathological features of GC or the 5-year OS rate was assessed by the OR with the corresponding 95\%CI. In the present study, an $\mathrm{OR}>1$ indicated a higher probability of tumor progression and poorer prognosis in patients with GC with CD44/CD44v6 overexpression. In the course of data pooling, statistical heterogeneity was evaluated by the Q-test. The $\mathrm{I}^{2}$ value indicates the degree of heterogeneity. A P-value $<0.10$ and/or $\mathrm{I}^{2}>50 \%$ signified significant heterogeneity, which necessitated the use of a random-effect model. Otherwise, a fixed-effect model was used[23]. Furthermore, we evaluated potential publication bias by funnel plot and Egger's linear regression test. The funnel plots were visually symmetrical, and the P-value of Egger's test was greater than 0.05 , which indicated no deviation among the studies. All statistical tests in this meta-analysis were twotailed and P-values $\leqslant 0.05$ were considered statistically significant. The statistical analyses were performed with STATA software version 12.0.

\section{Results}

Included studies and characteristics

A total of 1618 articles were initially retrieved based on the search strategy described above. After the titles and abstracts were reviewed, 1502 of the articles were excluded because they included non-human experiments or non-gastric-related studies or were non-original articles (e.g., review, letter). After evaluating the remaining articles, 72 records were excluded because they did not provide appropriate data. Eventually, 42 studies were included in the analysis. The flow diagram of the selection of eligible studies is shown in Fig. 1.

\section{Description of eligible literature \\ Of the 42 studies that} were used for the meta-analysis, total CD44 was reported in 21 papers $[5,16,18$,

Fig. 1. Flowchart of the eligible study selection process.

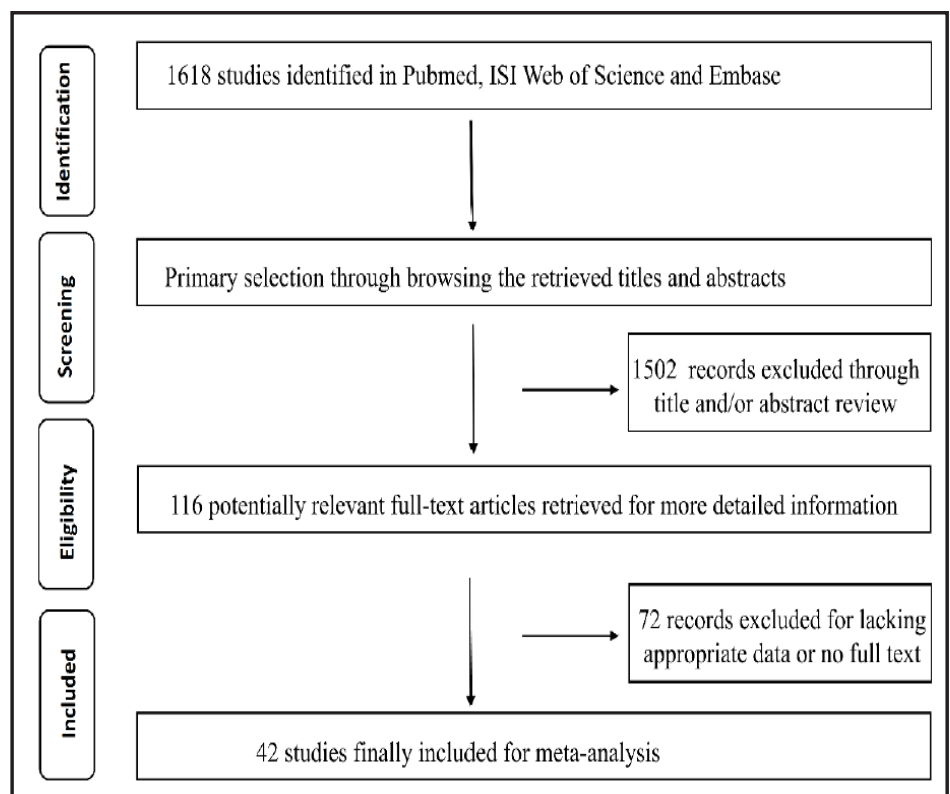




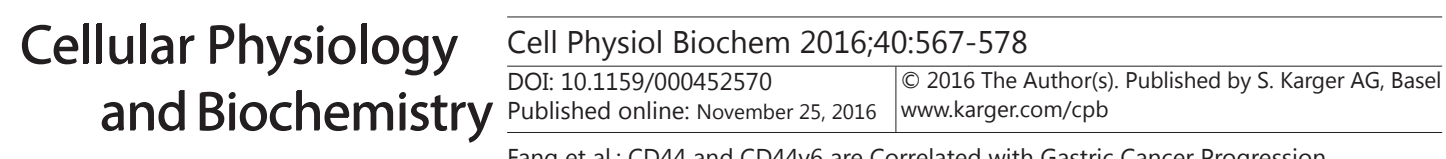

Fang et al.: CD44 and CD44v6 are Correlated with Gastric Cancer Progression

Table 1. Main characteristics of the included studies on total CD44. Abbreviations: NA, not available

\begin{tabular}{|c|c|c|c|c|c|c|c|c|}
\hline \multirow[b]{2}{*}{ Author } & \multirow[b]{2}{*}{ Year } & \multirow[b]{2}{*}{ Country } & \multirow[b]{2}{*}{ Cohort } & \multirow{2}{*}{$\begin{array}{l}\text { Tumor } \\
\text { stage }\end{array}$} & \multirow[b]{2}{*}{ Antibody } & \multirow[b]{2}{*}{ Cut-off } & \multicolumn{2}{|c|}{5 Year OS rate } \\
\hline & & & & & & & $\mathrm{CD} 44^{+}$ & CD44- \\
\hline Chen Jian Hui[41] & 2016 & China & 101 & I -III & Novus & 5 Score & $26.90 \%$ & $73.60 \%$ \\
\hline Liang Cao[38] & 2014 & China & 203 & NA & $\mathrm{BD}$ & 0 & \multicolumn{2}{|c|}{ NA } \\
\hline Yue Qiu[16] & 2014 & China & 243 & I $-I V$ & Abcam & 4 Score & \multicolumn{2}{|c|}{ NA } \\
\hline Lu Guoyu[36] & 2013 & China & 145 & $\mathrm{I}-\mathrm{IV}$ & NA & 3 Score & $15.90 \%$ & $59.20 \%$ \\
\hline Woon Yong Jung [35] & 2013 & Korea & 430 & I $-I V$ & Novocastra & NA & \multicolumn{2}{|c|}{ NA } \\
\hline Shi Chen [34] & 2013 & China & 152 & I $-\mathrm{IV}$ & Abcam & $65.00 \%$ & $29.50 \%$ & $54.10 \%$ \\
\hline Jian Wei Xie[37] & 2013 & China & 156 & I $-\mathrm{IV}$ & Abcam & 3 Score & \multicolumn{2}{|c|}{ NA } \\
\hline Han Suk Ryu[33] & 2012 & Korea & 276 & I $-\mathrm{IV}$ & $\mathrm{BD}$ & $5 \%$ & \multicolumn{2}{|c|}{ NA } \\
\hline Yuta Wakamatsu[5] & 2012 & Japan & 96 & I $-\mathrm{IV}$ & Novocastra & $10 \%$ & $56.00 \%$ & $62.10 \%$ \\
\hline Doventas[32] & 2012 & Turkey & 48 & I $-\mathrm{IV}$ & Zymed & 0 & \multicolumn{2}{|c|}{ NA } \\
\hline T Wang[31] & 2011 & Singapore & 106 & I $-\mathrm{IV}$ & Bender & 5 score & $27.70 \%$ & $66.70 \%$ \\
\hline S.Dhingra[30] & 2011 & USA & 138 & I $-\mathrm{IV}$ & Novocastra & NA & \multicolumn{2}{|c|}{$\mathrm{NA}$} \\
\hline Jung Yeon Kim[20] & 2009 & Korea & 210 & I $-\mathrm{IV}$ & Zymed & $10 \%$ & $46.00 \%$ & $46.90 \%$ \\
\hline Kamran. G[29] & 2008 & Iran & 100 & I $-\mathrm{IV}$ & Dako & $5 \%$ & $0.00 \%$ & $31.00 \%$ \\
\hline A.Nosrati[40] & 2004 & Iran & 95 & NA & Abcam & $5 \%$ & \multicolumn{2}{|c|}{ NA } \\
\hline Mee Joo[28] & 2003 & Korea & 99 & I - IV & Biogenex & $10 \%$ & \multicolumn{2}{|c|}{ NA } \\
\hline Chang Hak Yoo[27] & 1999 & Korea & 261 & II -III & Novocastra & $5 \%$ & $43.20 \%$ & $63.40 \%$ \\
\hline H.Isozaki[26] & 1998 & Japan & 108 & I $-\mathrm{IV}$ & Dako & $10 \%$ & \multicolumn{2}{|c|}{ NA } \\
\hline Ja Mun Chong[25] & 1997 & Japan & 104 & NA & $R \& D$ & NA & \multicolumn{2}{|c|}{ NA } \\
\hline Ruey Long Hong[24] & 1995 & China & 103 & NA & Sigma & 0 & \multicolumn{2}{|c|}{ NA } \\
\hline Barbara Mayer[18] & 1993 & Germany & 61 & NA & NA & NA & \multicolumn{2}{|c|}{ NA } \\
\hline
\end{tabular}

Table 2. Main characteristics of the included studies on CD44v6. Abbreviations: NA, not available

\begin{tabular}{|c|c|c|c|c|c|c|c|c|}
\hline \multirow[b]{2}{*}{ Author } & \multirow[b]{2}{*}{ Year } & \multirow[b]{2}{*}{ Country } & \multirow[b]{2}{*}{ Cohort } & \multirow{2}{*}{$\begin{array}{l}\text { Tumor } \\
\text { stage }\end{array}$} & \multirow[b]{2}{*}{ Antibody } & \multirow[b]{2}{*}{ Cut-off } & \multicolumn{2}{|c|}{5 Year OS rate } \\
\hline & & & & & & & $\mathrm{CD}_{4}^{+}{ }^{+}$ & CD44- \\
\hline Jian Wei Xie[17] & 2015 & China & 208 & I -IV & Abcam & 4 Score & $38.80 \%$ & $73.60 \%$ \\
\hline Xueyuan Cao[39] & 2014 & China & 290 & I $-I V$ & Thermo & 30 Sore & $50.50 \%$ & $58.50 \%$ \\
\hline Jian Wei Xie[37] & 2013 & China & 156 & I $-I V$ & Abcam & 3 Score & \multicolumn{2}{|c|}{ NA } \\
\hline Liang Yi Zhi[42] & 2012 & China & 59 & NA & NA & 0 Score & \multicolumn{2}{|c|}{ NA } \\
\hline Marcello.F[21] & 2012 & Brazil & 137 & I $-\mathrm{IV}$ & Novocastra & 0 & $46.40 \%$ & $58.60 \%$ \\
\hline Cristiana.B[43] & 2010 & Portugal & 43 & NA & Invitrogen & $25 \%$ & \multicolumn{2}{|c|}{ NA } \\
\hline H.Okayama[19] & 2009 & Japan & 135 & I -III & $R \& D$ & $5 \%$ & \multicolumn{2}{|c|}{ NA } \\
\hline Donghui Zhou[44] & 2007 & China & 103 & I $-\mathrm{IV}$ & NA & $10 \%$ & \multicolumn{2}{|c|}{ NA } \\
\hline I Songun[22] & 2005 & Netherlands & 285 & NA & Bender & $25 \%$ & $48.00 \%$ & $28.00 \%$ \\
\hline ZQ Zhao[45] & 2005 & China & 40 & I $-I V$ & NA & $5 \%$ & \multicolumn{2}{|c|}{ NA } \\
\hline Wojciech P.P[46] & 2004 & Poland & 19 & II -IV & Bender & $10 \%$ & \multicolumn{2}{|c|}{ NA } \\
\hline JQ Chen [47] & 2004 & China & 43 & I $-I V$ & Maixin & $10 \%$ & \multicolumn{2}{|c|}{ NA } \\
\hline Mee Joo[28] & 2003 & Korea & 99 & I $-I V$ & Biogenex & $10 \%$ & \multicolumn{2}{|c|}{ NA } \\
\hline Yong Li[48] & 2003 & China & 110 & I -IV & Santa Cruz & $5 \%$ & \multicolumn{2}{|c|}{ NA } \\
\hline A.Yamaguchi[49] & 2002 & Japan & 201 & I $-I V$ & NA & $0 \%$ & $63.30 \%$ & $33.40 \%$ \\
\hline Yan Xin[50] & 2001 & Ireland & 155 & I $-I V$ & $R \& D$ & $5 \%$ & \multicolumn{2}{|c|}{ NA } \\
\hline Yan Xin[51] & 2000 & Ireland & 170 & NA & NA & NA & \multicolumn{2}{|c|}{ NA } \\
\hline Hong Li[52] & 2000 & China & 74 & NA & Oncogene & NA & \multicolumn{2}{|c|}{ NA } \\
\hline K.Kurozumi[53] & 1998 & Japan & 98 & I - IIII & Bender & $30 \%$ & \multicolumn{2}{|c|}{ NA } \\
\hline H. Saito[54] & 1998 & Japan & 118 & I -IV & Bender & $5 \%$ & $41.90 \%$ & $75.60 \%$ \\
\hline W.Muller[55] & 1997 & Germany & 418 & NA & Bender Corp & $5 \%$ & \multicolumn{2}{|c|}{ NA } \\
\hline Hideki Ura[56] & 1996 & Japan & 110 & NA & $R \& D$ & $10 \%$ & \multicolumn{2}{|c|}{ NA } \\
\hline R.L Hong[24] & 1995 & China & 103 & NA & NA & $0 \%$ & \multicolumn{2}{|c|}{$\mathrm{NA}$} \\
\hline J.Mirecka[57] & 1995 & Poland & 105 & NA & Bender & NA & \multicolumn{2}{|c|}{ NA } \\
\hline
\end{tabular}

20, 24-41] and CD44v6 expression in 24 studies [17, 19, 21, 22, 24, 28, 37, 42-57]. The main characteristics of these studies are summarized in Table 1 and Table 2. However, in addition the antibody and dilution ratio, it is worth noting that no generalization regarding the cutoff value for defining positive CD44/ CD44v6 expression is presented. 
Fang et al.: CD44 and CD44v6 are Correlated with Gastric Cancer Progression

Table 3. Analysis of associations of total CD44 expression with clinical features. $\mathrm{P}_{\text {bias' }}$ the P-value of Egger's linear regression test for evaluating publication bias

\begin{tabular}{lccccc}
\hline & OR & $95 \% \mathrm{CI}$ & $\mathrm{P}$ & $\mathrm{I}^{2}$ & $\mathrm{P}_{\text {bias }}$ \\
\hline T category & 2.14 & $1.24-3.68$ & 0.006 & $82.10 \%$ & 0.083 \\
N category & 1.52 & $1.09-2.10$ & 0.012 & $71.30 \%$ & 0.224 \\
TNM stage & 1.98 & $1.18-3.31$ & 0.010 & $84.60 \%$ & 0.071 \\
Distant metastasis & 2.78 & $1.29-5.96$ & 0.009 & $75.00 \%$ & 0.079 \\
Lymphatic invasion & 1.34 & $1.01-1.77$ & 0.043 & $0.07 \%$ & 0.329 \\
Vascular invasion & 1.18 & $0.78-1.76$ & 0.435 & $0.01 \%$ & 0.464 \\
Tumor size & 1.02 & $0.60-1.72$ & 0.951 & $64.20 \%$ & 0.998 \\
Histological grade & 1.32 & $0.99-1.76$ & 0.055 & $54.60 \%$ & 0.747 \\
5 Year OS rate & 3.35 & $1.83-6.13$ & $<0.001$ & $72.80 \%$ & 0.255 \\
\hline
\end{tabular}

Fig. 2. Associations of total CD44 expression with clinical features. (A) T category; (B) $\mathrm{N}$ category; (C) distant metastasis; (D) lymphatic invasion; (E) TNM stage.

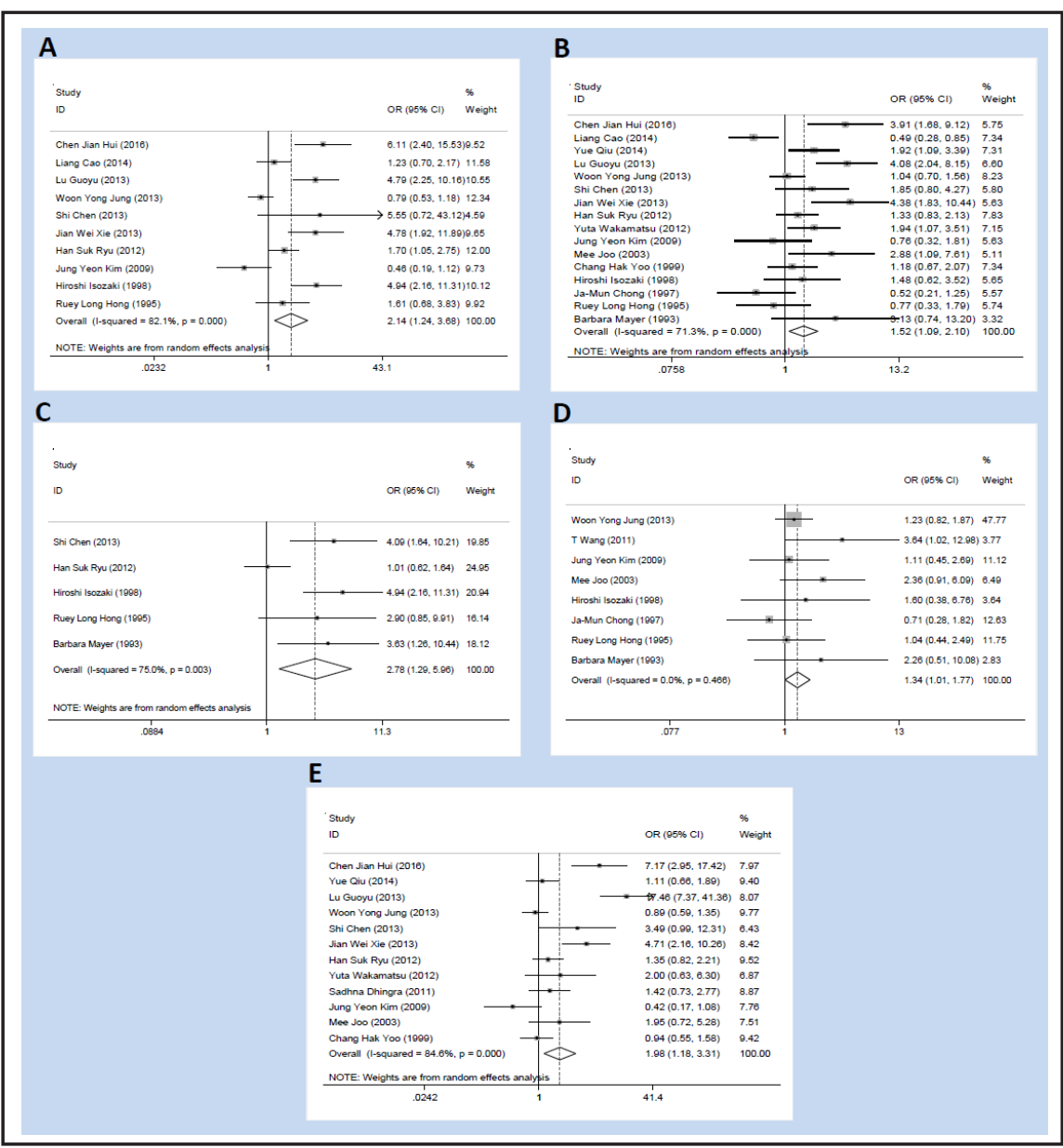

Correlation of total CD44 expression with the clinical features and 5-year OS rate of GC patients

The results of correlations between CD44 and the clinicopathological features of GC are presented in Table 3 and Fig. 2. The overall analysis showed that CD44 expression was statistically correlated with the $\mathrm{T}$ category $\left(\mathrm{T}_{1+2} \mathrm{vs}_{3+4}, \mathrm{OR}=2.14,95 \% \mathrm{CI}=1.24-3.68\right.$, $\mathrm{P}=0.006$, Fig. $2 \mathrm{~A})$, the $\mathrm{N}$ category $\left(\mathrm{N}_{0}\right.$ vs $\mathrm{N}_{1+2+3}, \mathrm{OR}=1.52,95 \% \mathrm{CI}=1.09-2.10, \mathrm{P}=0.012$, Fig. 2B), distant metastasis (NO vs YES, $\mathrm{OR}=2.78,95 \% \mathrm{CI}=1.29-5.96, \mathrm{P}=0.009$, Fig. $2 \mathrm{C}$ ), 
Fang et al.: CD44 and CD44v6 are Correlated with Gastric Cancer Progression

Table 4. Analysis associations of CD44v6 expression with clinical features. $\mathrm{P}_{\text {bias }}$, the P-value of Egger's linear regression test for evaluating publication bias. *, Excluding the study of I Songun et al., the correlation between CD44v6 expression and the 5-Year OS rate

\begin{tabular}{lccccc}
\hline & OR & $95 \%$ CI & P & $I^{2}$ & Pbias \\
\hline T category & 1.94 & $1.18-3.18$ & 0.009 & $79.5 \%$ & 0.294 \\
N category & 2.53 & $1.77-3.63$ & $<0.001$ & $68.7 \%$ & 0.001 \\
TNM stage & 3.64 & $1.85-7.16$ & $<0.001$ & $82.1 \%$ & 0.128 \\
Distant metastasis & 2.99 & $1.25-7.17$ & 0.014 & $\mathbf{0 . 0} \%$ & 0.893 \\
Lymphatic invasion & 1.68 & $1.31-2.16$ & $<0.001$ & $0.0 \%$ & 0.858 \\
Vascular invasion & 1.73 & $1.32-2.27$ & $<0.001$ & $\mathbf{0 . 0} \%$ & $\mathbf{0 . 8 0 5}$ \\
Tumor size & 1.09 & $0.50-2.39$ & 0.833 & $66.2 \%$ & $\mathrm{NA}$ \\
Histological grade & 1.15 & $0.76-1.75$ & 0.501 & $64.2 \%$ & 0.935 \\
5 Year OS rate & 1.97 & $0.83-4.70$ & 0.125 & $87.7 \%$ & 0.501 \\
5 Year OS rate* & 2.84 & $1.72-3.63$ & $<0.001$ & $50.3 \%$ & 0.428 \\
\hline
\end{tabular}

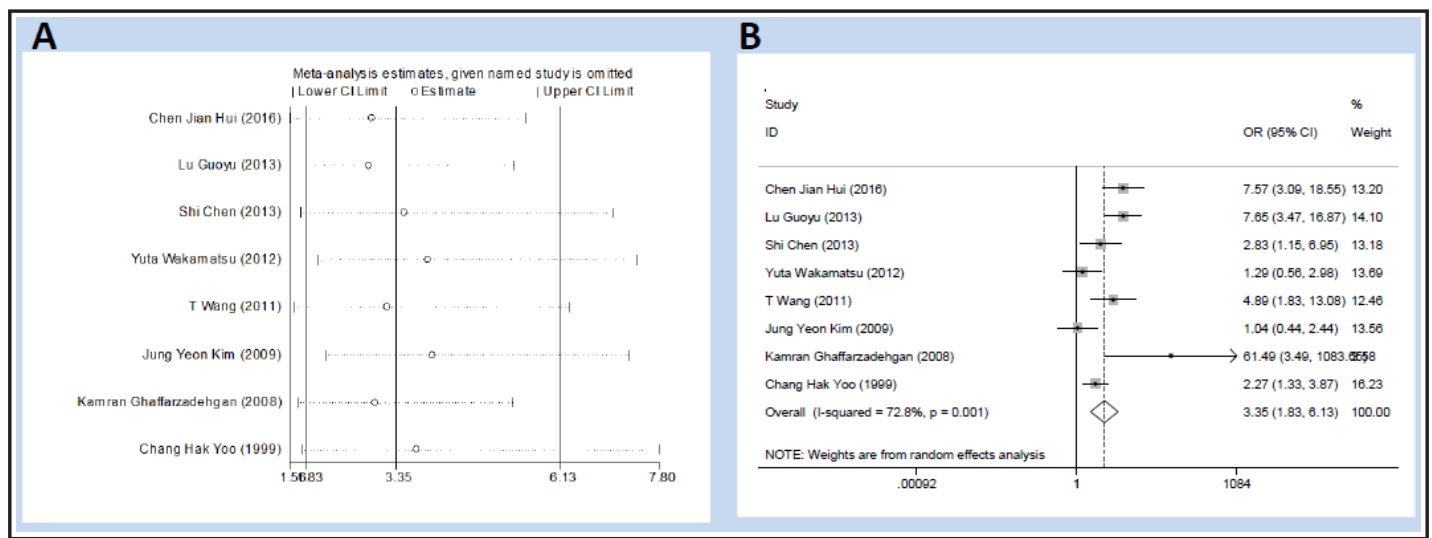

Fig. 3. Association between total CD44 expression and the 5-year OS rate. (A) The plot of sensitivity analysis for evaluating the association between total CD44 expression and the 5-year OS rate. (B) Forrest plot of OR for the correlation between total CD44 expression and the 5-year OS rate.

lymphatic invasion (NO vs YES, OR $=1.34,95 \% \mathrm{CI}=1.01-1.77, \mathrm{P}=0.043$, Fig. $2 \mathrm{D}$ ) and TNM stage (I/II vs III/IV, OR $=1.98,95 \% \mathrm{CI}=1.11-3.31, \mathrm{P}=0.010$, Fig. $2 \mathrm{E})$. Strictly speaking, higher expression of total CD44 indicated a higher T category, $\mathrm{N}$ category and TNM stage, as well as greater possibility of distant metastasis and lymphatic invasion. However, no clear correlation was found between total CD44 expression and tumor size $(\mathrm{OR}=1.02,95 \% \mathrm{CI}=$ $0.60-1.72, \mathrm{P}=0.951$ ), vascular invasion (NO vs YES, $\mathrm{OR}=1.18,95 \% \mathrm{CI}=0.78-1.76, \mathrm{P}=0.435$ ) or histological grade $(\mathrm{OR}=1.324,95 \% \mathrm{CI}=0.99-1.76, \mathrm{P}=0.055)$.

Furthermore, total CD44 expression was highly correlated with a lower 5-year OS rate $(\mathrm{OR}=3.35,95 \% \mathrm{CI}=1.83-6.13, \mathrm{P}<0.001$, Fig. $3 \mathrm{~A}-\mathrm{B})$. The data indicated that a poorer prognosis for GC patients with $\mathrm{CD} 44^{+}$tumors than those with $\mathrm{CD} 44^{-}$tumors.

Correlation of CD44v6 expression with the clinical features and 5-year OS rate of GC patients

Table 2 shows the correlations between CD44v6 and the clinical features of GC. The pooled analysis illustrated that CD44v6 expression was significantly associated with the $\mathrm{T}$ category $\left(\mathrm{T}_{1+2}\right.$ vs $\mathrm{T}_{3+4}, \mathrm{OR}=1.94,95 \% \mathrm{CI}=1.18-3.18, \mathrm{P}=0.009$, Fig. $\left.4 \mathrm{~A}\right), \mathrm{N}$ category $\left(\mathrm{N}_{0}\right.$ vs $\mathrm{N}_{1+2+3}, \mathrm{OR}=2.53,95 \% \mathrm{CI}=1.77-3.63, \mathrm{P}<0.001$, Fig. 4B), distant metastasis (NO vs YES, OR = $2.99,95 \% \mathrm{CI}=1.25-7.17, \mathrm{P}=0.002$, Fig. $4 \mathrm{C}$ ), lymphatic invasion (NO vs YES, OR $=1.68,95 \% \mathrm{CI}$ $=1.31-2.16, \mathrm{P}<0.001$, Fig. 4D), vascular invasion (NO vs YES, OR $=1.73,95 \% \mathrm{CI}=1.32-2.27$, 


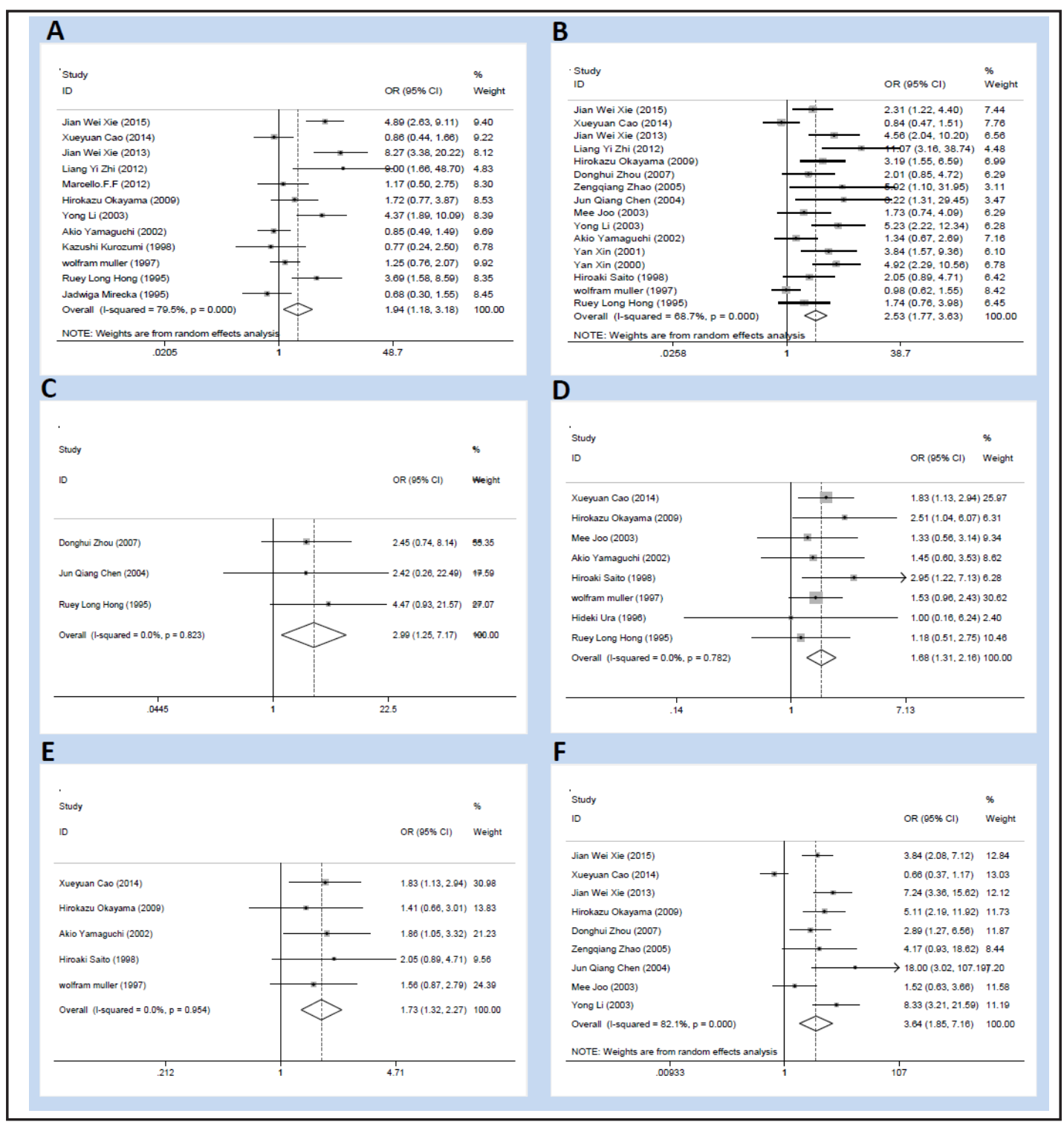

Fig. 4. Associations between CD44v6 expression and clinical features. (A) T category; (B) N category; (C) distant metastasis; (D) lymphatic invasion; (E) vascular invasion; (F) TNM stage.

$\mathrm{P}<0.001$, Fig. 4E), and TNM stage (I/II vs III/IV, pooled OR = 3.64, 95\%CI $=1.85-7.16, \mathrm{P}<$ 0.001 , Fig. $4 \mathrm{~F}$ ). In contrast, no associations were observed between CD44v6 expression and tumor size $(\mathrm{OR}=1.10,95 \% \mathrm{CI}=0.82-1.49, \mathrm{P}=0.526)$ or between $\mathrm{CD} 44 \mathrm{v} 6$ expression and histological grade $(\mathrm{OR}=0.87,95 \% \mathrm{CI}=0.60-1.27, \mathrm{P}=0.479)$, which was consistent with the analysis of total CD44.

The relationship between CD44v6 expression and the 5-year OS rate was evaluated in 6 cohorts. A sensitivity analysis revealed that the study by Songun et al. could alter the results of the analysis. After exclusion of this study, increased CD44v6 expression was found to be significantly associated with a lower 5 -year $\mathrm{OS}$ rate $(\mathrm{OR}=2.84,95 \% \mathrm{CI}=1.72-4.68$, $\mathrm{P}<0.001$, Fig. 5C) and the heterogeneity was decreased $\left(\mathrm{I}^{2}=50.3 \%\right.$ ) (Fig. 5D). However, when the study by Songun et al. was included, no correlation was observed between CD44v6 expression and the 5-year $\mathrm{OS}$ rate $(\mathrm{OR}=1.97,95 \% \mathrm{CI}=0.83-4.70, \mathrm{P}=0.125)$, and significant heterogeneity $\left(\mathrm{I}^{2}=87.7 \%\right)$ was observed (Fig. 5A-B and Table 3). 


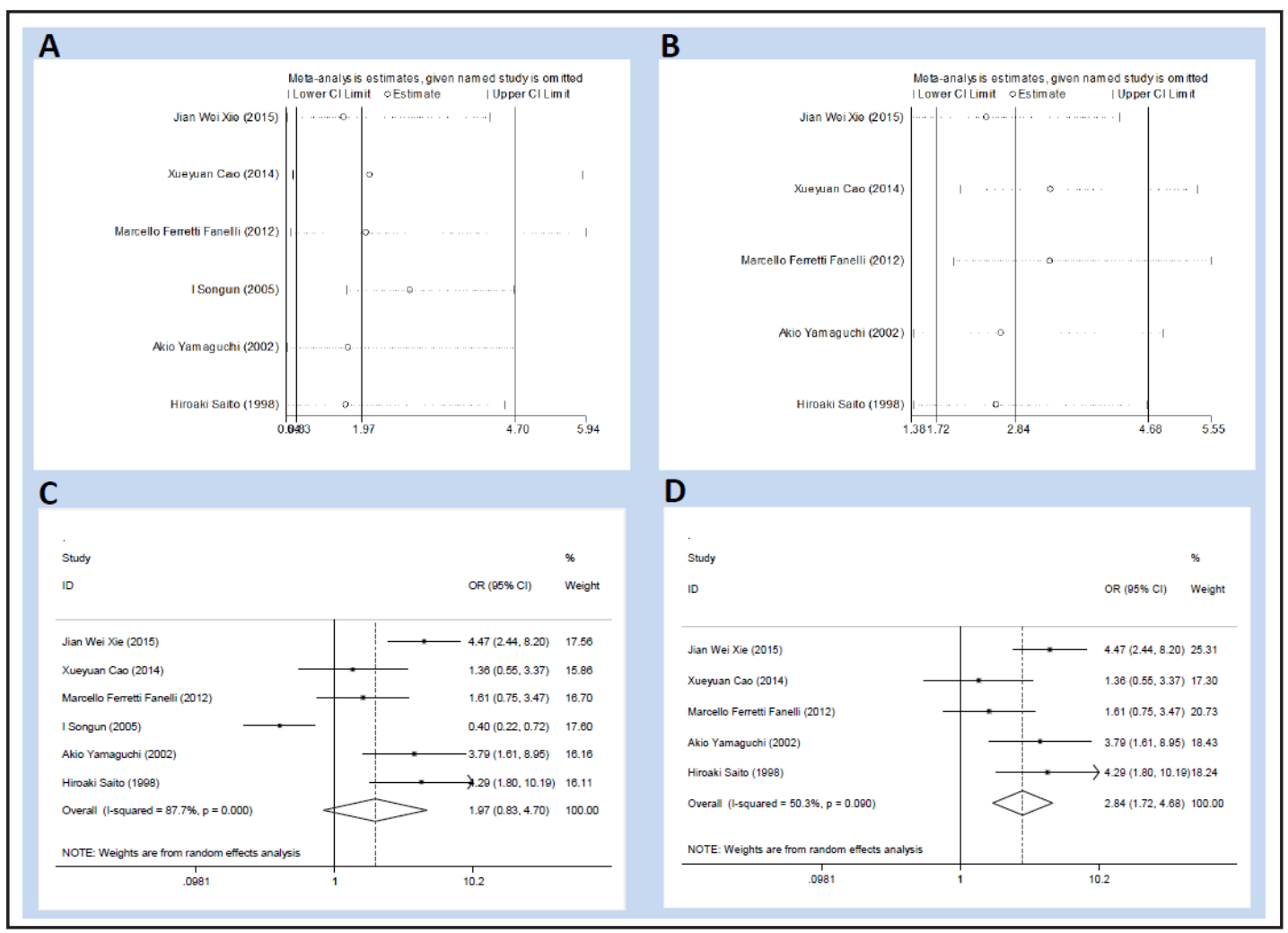

Fig. 5. Association between CD44v6 expression and the 5-year OS rate. When including I Songun et al. study: (A) sensitivity analysis plot for evaluating the association between CD44v6 expression and the 5-year OS rate; (B) Forrest plot of OR for the correlation between CD44v6 expression and the 5-year OS rate. After excluding the I Songun et al. study: (C) sensitivity analysis plot for evaluating the association between CD44v6 expression and the 5-year OS rate; (D) Forrest plot of OR for the correlation between CD44v6 expression and the 5-year OS rate.

\section{Discussion}

Although advances in diagnostic techniques and treatment methods have improved overall outcomes of patients with GC, the 5-year OS rate of these patients remains low [1], which may be a consequence of the occurrence of distant metastases, as evaluated by lymph node metastasis or vascular invasion [2,3]. Recently, some studies have suggested that CSCs are closely related to tumor progression, metastasis, and processes of treatment resistance in GC [58]. Notably, recent research has demonstrated that CD44-positive tumor cells posses CSC properties, such as self-renewal and tumorigenicity, and the presence of CSCs is typically regarded as a marker of poor prognosis in patients with GC [59].

Mayer et al. and Jian-Hui et al. indicated that higher expression of total CD44 is associated with a greater possibility of distant metastasis and higher TNM stages [18, 41]. CD44v6, one of the major variants of CD44, plays an important biological role in tumor invasion and metastasis. Indeed, Yamaguchi et al. demonstrated that positive CD44v6 expression of cancers is more frequently correlated with liver and hematogenous metastases [49]. Despite numerous studies, the validity of CD44 and CD44v6 as diagnostic or prognostic indicators in GC has not been fully investigated and some findings are controversial. Therefore, we performed a meta-analysis to reveal the relationship of CD44 and its isoform CD44v6 with the prognosis of patients with GC. Importantly, heterogeneity and sensitivity analyses were also performed to ensure the epidemiological credibility of this meta analysis. Here, we report high expression of total CD44 or CD44v6 to be positively associated with the T 


\section{Cellular Physiology Cell Physiol Biochem 2016;40:567-578

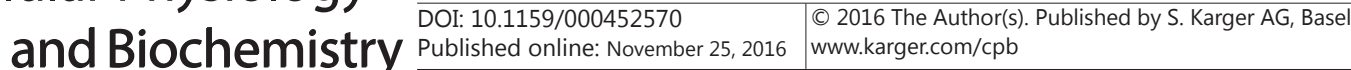 \\ Fang et al.: CD44 and CD44v6 are Correlated with Gastric Cancer Progression}

category, the $\mathrm{N}$ category, distant metastasis, lymphatic invasion and TNM stage. Moreover, CD44/CD44v6 overexpression predicts a low 5-year OS rate indicating that CD44 or CD44v6 could be used as a marker of poor prognosis in GC patients.

We first conducted a comprehensive meta-analysis to examine the relationship between total CD44 expression and the clinicopathological features of GC. CD44 positivity was found to be associated with certain clinicopathological features, such as the T category, the $\mathrm{N}$ category, distant metastasis, lymphatic invasion and TNM stage. We then assessed the relationship between CD44 expression and its prognostic significance in GC. The pooled data indicated that high total CD44 expression significantly predicted a lower 5-year OS rate. The results of our meta-analysis suggest that CD44 overexpression might contribute to the malignant progression of GC, which often leads to a poor prognosis.

We then investigated the pooled association between CD44v6 expression and the clinical features of GC, and the results were similar to those for CD44. However, no correlation was observed between CD44v6 expression and the 5-year OS rate, and the heterogeneity was significant. An additional sensitivity analysis revealed that the study by I Songun was the primary cause of this heterogeneity. After the study by I Songun was eliminated, the 5-year OS rate was significantly lower in GC patients with CD44-positive tumors than in those patients with CD44-negative tumors, and the heterogeneity was decreased.

It was notable that expression CD44 or CD44v6 was determined to have prognostic significance in GC according to our meta-analysis, which suggests that CD44/CD44v6 may be developed as potential prognostic factors for GC.

Several studies have shown that expression of CSC-related factors, including CD133, Lgr5, ALDH1 and Sox2, is associated with the progression of GC [30-32]. Future studies may reveal that co-expression of CSC markers associated with the prognosis of GC patients are valuable for clinical application.

Although we conducted a systematic and comprehensive analysis, certain limitations exist, and some results need to be carefully interpreted. First, we estimated the 5-year OS based on Kaplan-Meier curves derived from some of the original studies. These data might be less reliable than data from a direct analysis from the original paper. Second, despite an adjustment for heterogeneity through the use of random-effect model and sensitivity analyses, a high level of heterogeneity remained in some analyses. Third, a subset of the selected studies had a limited sample size, and it was therefore difficult to draw a definite conclusion on regarding prognostic value of CD44 among GC patients. Fourth, we did not find any significant deviation when assessing publication bias, but it is worth noting that positive results are likely to be published; thus, the association between high CD44 or CD44v6 expression and poor outcome of patients with GC might have surpassed our estimation. Furthermore, different antibodies and different cut-off values for determining positive CD44 or CD44v6 expression were used in the studies, which resulted in inconsistent conclusions.

\section{Conclusion}

In summary, although certain limitations exist, the results of the present study showed that high CD44 or CD44v6 expression is positively correlated with progression of gastric cancer. Additionally, CD44 or CD44v6 overexpression was found to be associated with a poorer prognosis of GC patients. Our results suggest that CD44 and CD44v6 may be useful diagnostic or prognostic biomarkers for GC and may be beneficial for novel targeted therapeutic strategies in the future. However, a future larger scale multicenter study may be needed to verify our results.

\section{Disclosure Statement}

The authors declare no competing financial interests. 


\section{Cellular Physiology Cell Physiol Biochem 2016;40:567-578

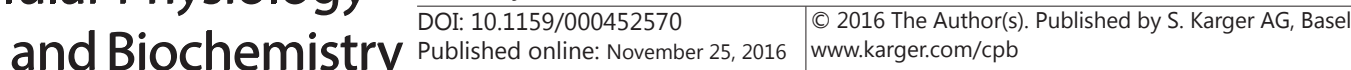

Fang et al.: CD44 and CD44v6 are Correlated with Gastric Cancer Progression

\section{References}

1 Jemal A, Bray F, Center MM, Ferlay J, Ward E, Forman D: Global cancer statistics. CA:2011;61:69-90.

2 Ajani JA: Gastroesophageal cancers: progress and problems. J Natl Compr Canc Netw 2008;6:813-814.

3 Valastyan S, Weinberg RA: Tumor metastasis: molecular insights and evolving paradigms. Cell 2011;147:275-292.

4 Reya T, Morrison SJ, Clarke MF, Weissman IL: Stem cells, cancer, and cancer stem cells. Nature 2001;414:105-111.

5 Wakamatsu Y, Sakamoto N, Oo HZ, Naito Y, Uraoka N, Anami K, Sentani K, Oue N, Yasui W: Expression of cancer stem cell markers ALDH1, CD44 and CD133 in primary tumor and lymph node metastasis of gastric cancer. Pathol Int 2012;62:112-119.

6 Wang D, Fan Z, Liu F, Zuo J: Hsa-miR-21 and Hsa-miR-29 in Tissue as Potential Diagnostic and Prognostic Biomarkers for Gastric Cancer. Cell Physiol Biochem 2015;37:1454-1462.

7 van der Windt GJ, Schouten M, Zeerleder S, Florquin S, van der Poll T: CD44 is protective during hyperoxiainduced lung injury. Am J Respir Cell Mol Biol 2011;44:377-383.

8 Volz Y, Koschut D, Matzke-Ogi A, Dietz MS, Karathanasis C, Richert L, Wagner MG, Mely Y, Heilemann M, Niemann HH, Orian-Rousseau V: Direct binding of hepatocyte growth factor and vascular endothelial growth factor to CD44v6. Biosci Rep DOI:10.1042/BSR20150093.

9 Preca BT, Bajdak K, Mock K, Sundararajan V, Pfannstiel J, Maurer J, Wellner U, Hopt UT, Brummer T, Brabletz S, Brabletz T, Stemmler MP: A self-enforcing CD44s/ZEB1 feedback loop maintains EMT and stemness properties in cancer cells. Int J Cancer 2015;137:2566-2577.

10 Li X, Ma X, Chen L, Gu L, Zhang Y, Zhang F, Ouyang Y, Gao Y, Huang Q, Zhang X: Prognostic value of CD44 expression in renal cell carcinoma: a systematic review and meta-analysis. Sci Rep 2015;5:13157.

11 Hu B, Luo W, Hu RT, Zhou Y, Qin SY, Jiang HX: Meta-Analysis of Prognostic and Clinical Significance of CD44v6 in Esophageal Cancer. Medicine 2015;94:e1238.

12 Zhao L, Gu C, Huang K, Zhang Z, Ye M, Fan W, Han W, Meng Y: The prognostic value and clinicopathological significance of CD44 expression in ovarian cancer: a meta-analysis. Arch Gynecol Obstet 2016; 294:10191029.

13 Chen J, Zhou J, Lu J, Xiong H, Shi X, Gong L: Significance of CD44 expression in head and neck cancer: a systemic review and meta-analysis. BMC cancer 2014;14:15.

14 Wielenga VJ, Smits R, Korinek V, Smit L, Kielman M, Fodde R, Clevers H, Pals ST: Expression of CD44 in Apc and Tcf mutant mice implies regulation by the WNT pathway. Am J Pathol 1999;154:515-523.

15 Bisson I, Prowse DM: WNT signaling regulates self-renewal and differentiation of prostate cancer cells with stem cell characteristics. Cell Res 2009;19:683-697.

16 Qiu Y, Hu Y, Zhang ZY, Ye L, Xu FH, Schneider ME, Ma XL, Du YX, Zuo XB, Zhou FS, Chen G, Xie XS, Zhang Y, Xia HZ, Wu JF, Du WD: Genetic association of osteopontin (OPN) and its receptor CD44 genes with susceptibility to Chinese gastric cancer patients. J Cancer Res Clin Oncol 2014;140:2143-2156.

17 Xie JW, Chen PC, Zheng CH, Li P, Wang JB, Lin JX, Lu J, Chen QY, Cao LL, Lin M, Lin Y, Huang CM: Evaluation of the prognostic value and functional roles of CD44v6 in gastric cancer. J Cancer Res Clin Oncol 2015;141:1809-1817.

18 Mayer B, Jauch KW, Gunthert U, Figdor CG, Schildberg FW, Funke I, Johnson JP: De-novo expression of CD44 and survival in gastric cancer. Lancet 1993;342:1019-1022.

19 Okayama H, Kumamoto K, Saitou K, Hayase S, Kofunato Y, Sato Y, Miyamoto K, Nakamura I, Ohki S, Sekikawa $\mathrm{K}$, Takenoshita S: CD44v6, MMP-7 and nuclear Cdx2 are significant biomarkers for prediction of lymph node metastasis in primary gastric cancer. Oncol Rep 2009;22:745-755.

20 Kim JY, Bae BN, Kim KS, Shin E, Park K: Osteopontin, CD44, and NFkappaB expression in gastric adenocarcinoma. Cancer Res Treat 2009;41:29-35.

21 Fanelli MF, Chinen LT, Begnami MD, Costa WL, Jr., Fregnami JH, Soares FA, Montagnini AL: The influence of transforming growth factor-alpha, cyclooxygenase-2, matrix metalloproteinase (MMP)-7, MMP-9 and CXCR4 proteins involved in epithelial-mesenchymal transition on overall survival of patients with gastric cancer. Histopathology 2012;61:153-161.

22 Songun I, Litvinov SV, van de Velde CJ, Pals ST, Hermans J, van Krieken JH: Loss of Ep-CAM (C017-1A) expression predicts survival in patients with gastric cancer. Br J Cancer 2005;92:1767-1772. 


\section{Cellular Physiology Cell Physiol Biochem 2016;40:567-578 \begin{tabular}{l|l|l|}
\hline DOI: 10.1159/000452570 & $\begin{array}{l}\text { C) 2016 The Author(s). Published by S. Karger AG, Basel } \\
\text { www.karger.com/cpb }\end{array}$
\end{tabular} \\ Fang et al.: CD44 and CD44v6 are Correlated with Gastric Cancer Progression}

23 Mantel N, Haenszel W: Statistical aspects of the analysis of data from retrospective studies of disease. J Natl Cancer Inst 1959;22:719-748.

24 Hong RL, Lee WJ, Shun CT, Chu JS, Chen YC: Expression of CD44 and its clinical implication in diffuse-type and intestinal-type gastric adenocarcinomas. Oncology 1995;52:334-339.

25 Chong JM, Fukayama M, Hayashi Y, Funata N, Takizawa T, Koike M, Muraoka M, Kikuchi-Yanoshita R, Miyaki M, Mizuno S: Expression of CD44 variants in gastric carcinoma with or without Epstein-Barr virus. Int J Cancer 1997;74:450-454.

26 Isozaki H, Ohyama T, Mabuchi H: Expression of cell adhesion molecule CD44 and sialyl Lewis A in gastric carcinoma and colorectal carcinoma in association with hepatic metastasis. Int J Cancer 1998;13:935-942.

27 Yoo CH, Noh SH, Kim H, Lee HY, Min JS: Prognostic significance of CD44 and nm23 expression in patients with stage II and stage IIIA gastric carcinoma. J Surg Oncol 1999;71:22-28.

28 Joo M, Lee HK, Kang YK: Expression of E-cadherin, beta-catenin, CD44s and CD44v6 in gastric adenocarcinoma: relationship with lymph node metastasis. Anticancer Res 2003;23:1581-1588.

29 Ghaffarzadehgan K, Jafarzadeh M, Raziee HR, Sima HR, Esmaili-Shandiz E, Hosseinnezhad H, TaghizadehKermani A, Moaven O, Bahrani M: Expression of cell adhesion molecule CD44 in gastric adenocarcinoma and its prognostic importance. World J Gastroenterol 2008;14:6376-6381.

30 Dhingra S, Feng W, Brown RE, Zhou Z, Khoury T, Zhang R, Tan D: Clinicopathologic significance of putative stem cell markers, CD44 and nestin, in gastric adenocarcinoma. Int J Clin Exp Pathol 2011;4:733-741.

31 Wang T, Ong CW, Shi J, Srivastava S, Yan B, Cheng CL, Yong WP, Chan SL, Yeoh KG, Iacopetta B, Salto-Tellez M: Sequential expression of putative stem cell markers in gastric carcinogenesis. Br J Cancer 2011;105:658665.

32 Doventas A, Bilici A, Demirell F, Ersoy G, Turna H, Doventas Y: Prognostic significance of CD44 and c-erb-B2 protein overexpression in patients with gastric cancer. Hepatogastroenterology 2012;59:2196-2201.

33 Ryu HS, Park DJ, Kim HH, Kim WH, Lee HS: Combination of epithelial-mesenchymal transition and cancer stem cell-like phenotypes has independent prognostic value in gastric cancer. Hum Pathol 2012;43:520528.

34 Chen S, Hou JH, Feng XY, Zhang XS, Zhou ZW, Yun JP, Chen YB, Cai MY: Clinicopathologic significance of putative stem cell marker, CD44 and CD133, in human gastric carcinoma. J Surg Oncol 2013;107:799-806.

35 Jung WY, Kang Y, Lee H, Mok YJ, Kim HK, Kim A, Kim BH: Expression of moesin and CD44 is associated with poor prognosis in gastric adenocarcinoma. Histopathology 2013;63:474-481.

36 Lu G, Wu X, Zhou L, Yu L, Wu S: Expressions of CD133 and CD44 in gastric adenocarcinoma and their relationship with E-cadherin expression. Nan fang yi ke da xue xue bao 2013;33:1632-1637.

37 Xie JW, Huang CM, Zheng CH, Li P, Wang JB, Lin JX, Lu J: Expression tumor stem cell surface marker CD44 in gastric cancer and its significance. Zhonghua wei chang wai ke za zhi 2013;16:1107-1112.

38 Cao L, Hu X, Zhang J, Liang P, Zhang Y: CD44(+) CD324(-) expression and prognosis in gastric cancer patients. J Surg Oncol 2014;110:727-733.

39 Cao X, Cao D, Jin M, Jia Z, Kong F, Ma H, Wang Y, Jiang J: CD44 but not CD24 expression is related to poor prognosis in non-cardia adenocarcinoma of the stomach. BMC Gastroenterol 2014;14:157.

40 Nosrati A, Naghshvar F, Khanari S: Cancer Stem Cell Markers CD44, CD133 in Primary Gastric Adenocarcinoma. Int J Mol Cell Med 2014;3:279-286.

41 Jian-Hui C, Er-Tao Z, Si-Le C, Hui W, Kai-Ming W, Xin-Hua Z, Chuang-Qi C, Shi-Rong C, Yu-Long H: CD44, Sonic Hedgehog, and Gli1 Expression Are Prognostic Biomarkers in Gastric Cancer Patients after Radical Resection. Gastroenterol Res Pract 2016;2016:1013045.

42 Liang YZ, Fang TY, Xu HG, Zhuo ZQ: Expression of CD44v6 and Livin in gastric cancer tissue. Chin Med J 2012;125:3161-3165.

43 da Cunha CB, Oliveira C, Wen X, Gomes B, Sousa S, Suriano G, Grellier M, Huntsman DG, Carneiro F, Granja PL, Seruca R: De novo expression of CD44 variants in sporadic and hereditary gastric cancer. Lab Invest 2010;90:1604-1614.

44 Zhou DH, Ma ZM, Chen Y: Expression and clinical significance of CD44v6 and sCD44v6 in gastric carcinoma. Zhonghua zhong liu za zhi 2007;29:833-837.

45 Zhao ZQ, Yu PW, Zhao YL, Shi Y: Expressions of RhoC, CD44v6 and ICAM-1 in human gastric cancer and its clinicopathological significance. Zhonghua wei chang wai ke za zhi 2005;8:352-355. 


\section{Cellular Physiology Cell Physiol Biochem 2016;40:567-578 \begin{tabular}{ll|l} 
DOI: 10.1159/000452570 & $\begin{array}{l}\text { O 2016 The Author(s). Published by S. Karger AG, Basel } \\
\text { www.karger.com/cpb }\end{array}$
\end{tabular} \\ Fang et al.: CD44 and CD44v6 are Correlated with Gastric Cancer Progression}

46 Polkowski WP, Skomra DG, Mielko J, Wallner GT, Szumilo J, Zinkiewicz K, Korobowicz EM, van Lanschot JJ: E-cadherin expression as predictive marker of proximal resection line involvement for advanced carcinoma of the gastric cardia. Eur J Surg Oncol 2004;30:1084-1092.

47 Chen JQ, Zhan WH, He YL, Peng JS, Wang JP, Cai SR, Ma JP: Expression of heparanase gene, CD44v6, MMP-7 and nm23 protein and their relationship with the invasion and metastasis of gastric carcinomas. World J Gastroenterol 2004;10:776-782.

48 Li Y, Zhang JH, Kuang G, Yang JQ, Zhao Q, Wang XL, Jiao ZK, Zhang ZD, Wang LL: Expression of MUC1, CD44v6, nm23 in gastric carcinomas and regional lymph node tissues and their association with invasion, metastasis, and prognosis of the tumor. Ai zheng 2003;22:985-989.

49 Yamaguchi A, Goi T, Yu J, Hirono Y, Ishida M, Iida A, Kimura T, Takeuchi K, Katayama K, Hirose K: Expression of CD44v6 in advanced gastric cancer and its relationship to hematogenous metastasis and long-term prognosis. J Surg Oncol 2002;79:230-235.

50 Xin Y, Grace A, Gallagher MM, Curran BT, Leader MB, Kay EW: CD44V6 in gastric carcinoma: a marker of tumor progression. Appl Immunohistochem Mol Morphol2001;9:138-142.

51 Yan X, Yanping W, Sumin Z, Dongying W, Lei X, Yinchang Z: Relationship between CD44v6 expression and metastatic potential and prognosis in gastric carcinoma. Chin Med Sci J 2000;15:128.

52 Li H, Guo L, Li JW, Liu N, Qi R, Liu J: Expression of hyaluronan receptors CD44 and RHAMM in stomach cancers: relevance with tumor progression. Int J Oncol 2000;17:927-932.

53 Kurozumi K, Nishida T, Nakao K, Nakahara M, Tsujimoto M: Expression of CD44 variant 6 and lymphatic invasion: importance to lymph node metastasis in gastric cancer. World J Surg 1998;22:853-857.

54 Saito H, Tsujitani S, Katano K, Ikeguchi M, Maeta M, Kaibara N: Serum concentration of CD44 variant 6 and its relation to prognosis in patients with gastric carcinoma. Cancer 1998;83:1094-1101.

55 Muller W, Schneiders A, Heider KH, Meier S, Hommel G, Gabbert HE: Expression and prognostic value of the CD44 splicing variants v5 and v6 in gastric cancer. J Pathol 1997;183:222-227.

56 Ura H, Denno R, Hirata K: Correlation between nm23 protein and several cell adhesion molecules in human gastric carcinoma. Jpn J Cancer Res 1996;87:512-517.

57 Mirecka J, Marx D, Schauer A: Immunohistochemical localization of CD44 variants 5 and 6 in human gastric mucosa and gastric cancer. Anticancer Res 1995;15:1459-1465.

58 Li K, Dan Z, Nie YQ: Gastric cancer stem cells in gastric carcinogenesis, progression, prevention and treatment. World J Gastroenterol 2014;20:5420-5426.

59 Rassouli FB, Matin MM, Saeinasab M: Cancer stem cells in human digestive tract malignancies. Tumour Biol 2016;37:7-21. 